\title{
PHYSICAL AND CHEMICAL PRETREATMENT OF SUGARCANE BAGASSE FOR ENHANCED ACID HYDROLYSIS
}

\author{
JANAÍNA ALVES CARVALHO, ${ }^{*}$ MATHEUS FELIPE FREIRE PEGO, ${ }^{* *}$ \\ PAULO RICARDO GHERARDI HEIN, ${ }^{* *}$ WILLIAN MIGUEL DA SILVA BORGES ${ }^{* * *}$ and \\ MARIA LÚCIA BIANCHI* \\ "Department of Chemistry (DQI), Federal University of Lavras, 37200-000, Mailbox 3037, \\ Lavras, $M G$, Brazil \\ ${ }^{* *}$ Department of Forestry Sciences (DCF), Federal University of Lavras, 37200-000, Mailbox 3037, Lavras, \\ $M G$, Brazil \\ 凶Corresponding author: W. M. da Silva Borges, will_msb@hotmail.com
}

Received August 22, 2019

The second-generation ethanol production process proceeds in several stages. One of them is the pretreatment of lignocellulosic materials, which consists in the disruption of vegetal fibers, promoting partial removal of lignin and hemicelluloses. Pretreatment methods are of great importance to the effectiveness of the hydrolysis stage due to the increase in accessibility of hydrolysis reagents to the interior of the fibers, improving the conversion of lignocellulosic materials. In this study, a pretreatment of sugarcane bagasse was performed, involving milling and ultrasound treatment in alkaline or acidic medium. After the pretreatments, the materials were submitted to acid hydrolysis reactions. To evaluate the efficiency of the pretreatments, the amount of total reducing sugars (\% TRS) of the hydrolysis products were assessed. The best results were obtained for the alkaline pretreatment of sugarcane bagasse, with almost $20 \%$ of TRS.

Keywords: biomass, second-generation ethanol, glucose, reducing sugar

\section{INTRODUCTION}

Sugarcane bagasse is one of the most important sub-products in sugar and alcohol mills in Brazil. This material contains, on average, 40 to $50 \%$ cellulose, 15 to $25 \%$ hemicelluloses and 20 to $30 \%$ lignin, as well as ash (composed mainly of $\mathrm{SiO}_{2}$ ) and other components. ${ }^{1-2}$ These values vary according to species, planting methodology, cutting season, etc. An estimate of CONAB (Brazilian National Supply Company) indicated a sugarcane production of around 615 million tons in 2019, which was expected to generate almost 180 million of tons of bagasse an incredible source of cellulose for obtaining glucose. ${ }^{3}$ Thus, the pretreatment of sugarcane bagasse is one of the most relevant stages in the process of biofuel production.

As cellulose has crystalline regions distributed in the fibers, its large conversion to glucose, by means of hydrolysis, using clean and viable methods, is still a challenge. Cellulose fibers are strongly bound to other constituents of the material, making them difficult to access by hydrolysis agents, which cannot efficiently break the glycosidic bonds to release the monosaccharides. ${ }^{4}$ Several pretreatment methods (physical, chemical, biological or a combination of these methods) have been proposed and developed, each one with its advantages and disadvantages. $^{5-7}$

Grinding is classified as a physical pretreatment and can be performed in several types of mills. This process decreases the particle size of the solid material, increasing its specific surface area and the rate of the reaction. ${ }^{8-9}$

Some of the most common chemical pretreatments are based on the use of alkalis, such as sodium hydroxide, as well as on the use of acids, such as hydrochloric or sulfuric acid. ${ }^{10-11}$

Some researchers have demonstrated that cellulose saccharification was enhanced by using sonication due to the intense vibration of the molecules, generating heat and causing structural 
changes in the cellulosic fibers. ${ }^{12-14}$ In some cases, the sonication changes the crystallinity and the polymerization degree of cellulose, increasing the soluble fraction of the fibrils and reducing the chain size.

In this context, this study aimed to evaluate the efficiency of a pretreatment (milling and sonication in alkali or acid medium) of sugarcane bagasse in contributing to cellulose conversion to glucose, during acid hydrolysis.

\section{EXPERIMENTAL}

\section{Material}

Sugarcane bagasse was provided by Biosev Industry, in Lagoa da Prata, Minas Gerais State, Brazil.

\section{Sugarcane bagasse pretreatment}

Sugarcane bagasse was milled in a Marconi ${ }^{\circledR}$ ball mill. After that, the material was classified granulometrically by using sieves of 200, 100, 60 and 40 mesh. To evaluate the best results, acid hydrolysis of all the materials, with different particle size, was performed and the \% TRS (total reducing sugars) was determined.

We used a pretreatment with a sonication frequency of $20 \mathrm{kHz}$ and a maximum power of $150 \mathrm{~W}$ in acidic or alkaline medium, with $5 \mathrm{~g}$ of sugarcane bagasse with a particle size of 40 mesh and $50 \mathrm{~mL}$ of $\mathrm{HCl} 2 \%(\mathrm{v} / \mathrm{v})$ or $\mathrm{NaOH} 5 \%(\mathrm{~m} / \mathrm{v})$ solution in a $250 \mathrm{~mL}$ Erlenmeyer flask. The experiment was conducted at room temperature in an ultrasound bath ECEL (Alpha 3L e Alpha 3L PLUS) 50/60 Hz for 15, 30 and $60 \mathrm{~min}$.

\section{Acidic hydrolysis}

After performing the pretreatments, the materials obtained were subjected to acid hydrolysis to obtain monosaccharides. Acidic hydrolysis was carried out in a closed system, using a stainless steel batch reactor, equipped with a magnetic stirrer, a pressure gauge and a temperature controller in an oil bath. Approximately $0.1 \mathrm{~g}$ of bagasse (pretreated or untreated) and $7 \mathrm{~mL}$ of $0.1 \%(\mathrm{v} / \mathrm{v})$ hydrochloric acid solution were used. The reaction was conducted at $170{ }^{\circ} \mathrm{C}$ for $60 \mathrm{~min}$.

After the reaction, the reactor was rapidly cooled to room temperature with flowing water. The liquid phase was collected by filtration, neutralized with $0.1 \%(\mathrm{~m} / \mathrm{v})$ $\mathrm{NaOH}$ solution and stored for further analysis.

\section{Determination of total reducing sugars (TRS)}

Total reducing sugar content (\%TRS) of the neutralized hydrolysates was determined by the dinitrosalicylic acid method (DNS), developed by Miller, ${ }^{15}$ with some adjustments.

The pretreated samples that had the best \%TRS results were chosen for further analysis: X-ray diffraction (to determine crystallinity), optical microscopy (to evaluate the physical changes in the fibers) and HPLC (to determine the amount of glucose in the hydrolysates) were performed (Table 1). The choice of samples was based on the \%TRS values.

\section{X-ray diffraction (XRD)}

Pretreated and untreated sugarcane bagasse samples were analyzed by X-ray diffraction (XRD) in Shimadzu XRD-6000 equipment, with $\mathrm{Cu}-\mathrm{K} \alpha$ radiation $(\lambda=1.5406 \AA)$ and $0.02^{\circ} \mathrm{s}^{-1}$ step, using graphite crystal as monochromator. The crystallinity index was calculated by an empirical method developed by Segal ${ }^{16}$ (Eq. 1):

$I_{c}=\frac{I_{002}-I_{a m}}{I_{002}} \times 100$

where $I_{002}$ is the maximum intensity of the reflection a $\mathrm{t} 2 \Theta=22.5^{\circ}$ and $I_{a m}$ is the intensity of diffraction at $2 \Theta=18^{\circ}$, for cellulose.

Table 1

Selected samples for X-ray diffraction, optical microscopy and HPLC analysis

\begin{tabular}{lccc}
\hline Samples & Reagent & $\begin{array}{c}\text { Conc. } \\
(\%)\end{array}$ & $\begin{array}{c}\text { Sonication time } \\
(\mathrm{min})\end{array}$ \\
\hline $2 \% \mathrm{HCl}-30 \mathrm{~min}$ & $\mathrm{HCl}$ & $2(\mathrm{v} / \mathrm{v})$ & 30 \\
$2 \% \mathrm{HCl}-60 \mathrm{~min}$ & $\mathrm{HCl}$ & $2(\mathrm{v} / \mathrm{v})$ & 60 \\
$5 \% \mathrm{NaOH}-30 \mathrm{~min}$ & $\mathrm{NaOH}$ & $5(\mathrm{~m} / \mathrm{v})$ & 30 \\
$5 \% \mathrm{NaOH}-60 \mathrm{~min}$ & $\mathrm{NaOH}$ & $5(\mathrm{~m} / \mathrm{v})$ & 60 \\
Untreated & \multicolumn{2}{c}{ Untreated sugarcane bagasse } \\
\hline
\end{tabular}

\section{Optical microscopy}

Pretreated and untreated sugarcane bagasse materials were analyzed by optical microscopy to determine fiber dimensions before and after the pretreatments. The material was prepared according to the Nicholls and Dadswell method, described by Ramalho. ${ }^{3}$ This method uses $\mathrm{H}_{2} \mathrm{O}_{2} 30 \%$ and acetic acid as a maceration solution. For fiber analysis, a Nikon
Eclipse E-200 LED Microscope and Dino Capture software were used. Temporary slides were prepared, one for each pretreatment, and twenty measurements were performed for each slide. The results presented were obtained from the averages of 20 measurements.

High performance liquid chromatography (HPLC) Chromatographic analyses of the hydrolysates from 
pretreated sugarcane bagasse were conducted to evaluate the glucose amount. Quantitative analyses of glucose were carried out via high performance liquid chromatography (HPLC) in Shimadzu equipment, with a electrochemical detector (Antec, Decade II model). The chromatographic column used was an ion exchange one (Carbopac PA1) and the analyses were conducted in the pulsed mode. $20 \mathrm{mmol} \mathrm{L}^{-1}$ of $\mathrm{NaOH}$ solution was used as eluent, at a flow rate of $0.2 \mathrm{~mL}$ $\min ^{-1}$ and oven temperature of $44{ }^{\circ} \mathrm{C}$. A standard glucose sugar curve was prepared, following the same procedures for the analyses, which allowed quantitative sugar identification through peak area correlation.

\section{RESULTS AND DISCUSSION}

\section{Influence of granulometry on the amount of} TRS

Biomass has a complex structure and it is very resistant to reactions; the efficiency in obtaining glucose from cellulose of a given feedstock depends of many factors, such as lignin content, accessibility of cellulose, crystallinity, degree of polymerization of cellulose, hemicelluloses and fiber strength. ${ }^{17-19}$ Thus, pretreatment stages are performed aiming to disaggregate the lignincarbohydrate matrix, making the cellulose and part of the hemicelluloses more accessible for the saccharification reaction. The influence of the sugarcane bagasse particle size $(40,60,100$ and 200 mesh) on the \%TRS obtained after the hydrolysis reaction was studied (Fig. 1).

It is observed that the particle size does not influence the \%TRS obtained after the reactions, even when compared to untreated bagasse (used as received).

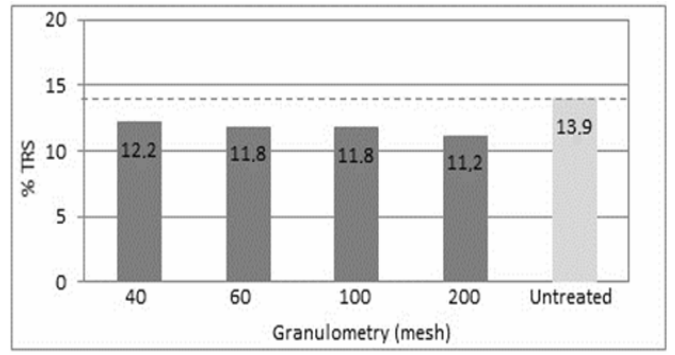

Figure 1: \% TRS in hydrolysis products of sugarcane bagasse of different particle size
Although grinding can increase the surface area of the material, it was not efficient and did not increase the accessibility of the hydrolysis reagents to the interior of the fibers. Consequently, it did not promote an increase in the quantity of sugars obtained. This is advantageous since the material does not need to undergo grinding processes before the reaction. The sugarcane bagasse is composed of particles of different sizes and shapes, ${ }^{20}$ so for the next stages of the work, although the milling did not influence the results of the reactions, it was decided to use sugarcane bagasse of 40-mesh particle size. This leaves the material more homogeneous and facilitates the analysis and comparison of subsequent results.

\section{Sonication in acidic or alkaline medium}

Sugarcane bagasse hydrolysis reactions were performed without pretreatment (40 mesh) and with pretreatment with ultrasound at different times $(15,30$ and $60 \mathrm{~min})$ in acidic $(0.002 \%$ and $2 \% \mathrm{HCl}(\mathrm{v} / \mathrm{v}))$ or alkaline $(0.005 \%$ and $5 \% \mathrm{NaOH}$ $(\mathrm{m} / \mathrm{v}))$ medium. The results of $\%$ TRS found for each hydrolysis experiment are shown in Figure 2.

It was observed that the pretreatments carried out in $0.002 \%$ or $2 \% \mathrm{HCl}(\mathrm{v} / \mathrm{v})$ and $0.005 \%$ $\mathrm{NaOH}(\mathrm{m} / \mathrm{v})$ did not contribute positively to an increase in \%TRS, regardless of the ultrasound exposure time. However, the pretreatment performed in $5 \% \mathrm{NaOH}(\mathrm{m} / \mathrm{v})$ promoted an increase in \%TRS, after $30 \mathrm{~min}$ of ultrasound exposure.

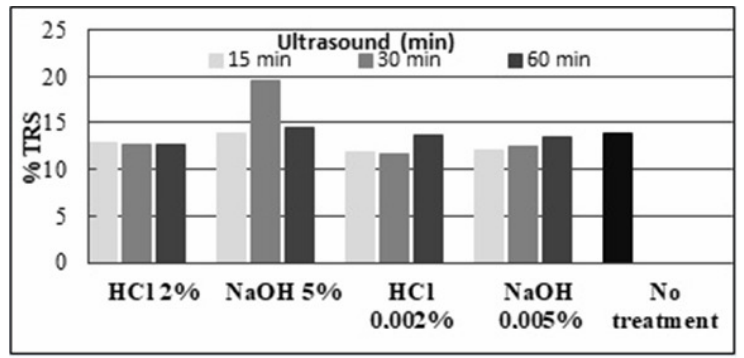

Figure 2: Effect of $\mathrm{HCl}$ and $\mathrm{NaOH}$ pretreatment on $\%$ TRS 


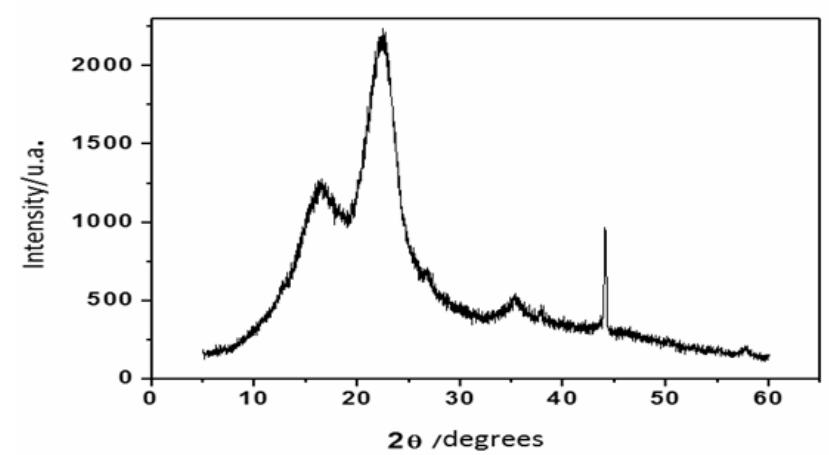

Figure 3: X-ray diffractogram of untreated sugarcane bagasse

Table 2

Crystallinity Index (CI), total reducing sugars (\% TRS) and size (length, width, thickness) of pretreated and untreated sugarcane bagasse fibers

\begin{tabular}{lccccc}
\hline Sugarcane bagasse & $\begin{array}{c}\text { TRS } \\
(\%)\end{array}$ & $\begin{array}{c}\text { CI } \\
(\%)\end{array}$ & $\begin{array}{c}\text { Length } \\
(\mu \mathrm{m})\end{array}$ & $\begin{array}{c}\text { Width } \\
(\mu \mathrm{m})\end{array}$ & $\begin{array}{c}\text { Thickness } \\
(\mu \mathrm{m})\end{array}$ \\
\hline $2 \% \mathrm{HCl}-30 \mathrm{~min}$ & 12.7 & 58.4 & 755.3 & 19.1 & 5.0 \\
$5 \% \mathrm{NaOH}-30 \mathrm{~min}$ & 19.5 & 59.7 & 755.6 & 20.1 & 4.7 \\
$2 \% \mathrm{HCl}-60 \mathrm{~min}$ & 12.5 & 52.2 & 697.8 & 18.1 & 5.2 \\
$5 \% \mathrm{NaOH}-60 \mathrm{~min}$ & 14.5 & 57.4 & 534.4 & 18.5 & 4.8 \\
Untreated & 13.9 & 51.9 & $>1000$ & 24.8 & 5.3 \\
\hline
\end{tabular}

It is believed that sugarcane bagasse fibers treated with $5 \% \mathrm{NaOH}(\mathrm{m} / \mathrm{v})$ have better performance in the hydrolysis reactions, since they have more hydrophilic characteristics that improve the absorption of the hydrolysis reagents and the efficiency of the reaction. Carvalho et $a l .^{21}$ studied the effect of pretreatment of carnauba straw fibers with $1 \% \mathrm{NaOH}(\mathrm{m} / \mathrm{v})$ and $5 \% \mathrm{NaOH}$ $(\mathrm{m} / \mathrm{v})$ on their water absorption and observed that fibers treated with more concentrated alkaline solution showed greater water absorption.

According to Alvira et al., ${ }^{22}$ alkaline pretreatments increase the digestibility of cellulose and are more effective in solubilizing lignin (hydrophobic), exposing cellulose and causing less solubilization of hemicelluloses (hydrophilic), when compared to pretreatments using acids or hydrothermal processes. Furthermore, $\mathrm{NaOH}$ causes swelling, increasing the inner surface of cellulose, reducing the degree of polymerization. The exposure period to ultrasound $(15,30$ and $60 \mathrm{~min})$ did not influence the results, except for $5 \% \mathrm{NaOH}(\mathrm{m} / \mathrm{v})$, in which the highest \%TRS was found when sonication was conducted for $30 \mathrm{~min}$.

\section{X-ray diffractometry (XRD) and optical microscopy analyses}

The X-ray diffractogram of untreated sugarcane bagasse is shown in Figure 3. The peak intensities are related to the crystallinity of the materials. $^{22}$ The crystallinity index (CI) was calculated according to Equation 1, using the data from the diffractograms.

The values of $\mathrm{CI}$ for the pretreated and untreated bagasse are shown in Table 2. The bagasse pretreated under alkaline conditions presented higher values of \% TRS and \% CI, since the $\mathrm{NaOH}$ seems to cause more changes in the structure of the lignin and hemicelluloses than $\mathrm{HCl}$. The pretreatment with $\mathrm{NaOH}$ or $\mathrm{HCl}$ promotes the partial solubilization of the lignin and hemicelluloses, which are amorphous materials. In this way, the amount of the crystalline component (cellulose) in the bagasse is relatively increased, which consequently increases the CI values.

Both treated and untreated sugarcane bagasse fibers were subjected to optical microscopy analyses to measure their length, width and thickness. Measurements were performed on twenty replicates for each sample and the final result was obtained from the average of the measurements taken. Table 2 shows the average values calculated for the length, width and thickness of sugarcane bagasse fibers, with and without pretreatment.

In general, the pretreatments did not cause any 
marked damage to the fibers. It was observed that there were no significant differences among fiber dimensions for the pretreated materials. However, there were differences when comparing pretreated materials with the untreated one. There was a decrease in the length of the pretreated fibers and a small decrease in width (in relation to the untreated material). The wall thickness does not appear to have undergone any modification.

\section{Quantification of glucose obtained in hydrolysis reactions}

Figure 4 shows the amount of glucose obtained as a product of the hydrolysis reactions of the pretreated materials and the untreated sugarcane bagasse. It is important to mention that \%TRS provides the total amount of sugars formed, part of which is glucose. In general, greater amounts of glucose were found in the products obtained from the acid hydrolysis of sugarcane bagasse pretreated in alkaline medium, if compared to the untreated one and the sample pretreated in acid medium.



Figure 4: Glucose levels analyzed by HPLC

The loss of part of the lignin content and a small reduction in the hemicelluloses of the sugarcane bagasse are common in grasses treated with alkaline solutions. ${ }^{23}$ In addition to the loss of the amorphous and hydrophobic material (lignin), it is believed that during the pretreatment fiber swelling occurs, increasing the moisture content in between the cellulose fibers, which become more available, facilitating the attack of hydrolysis reagents.

\section{CONCLUSION}

It was found that the grinding of the material to different grades $(40,60,100,200$ mesh) did not influence the amount of total reducing sugars (\% TRS) obtained after hydrolysis.

Sugarcane bagasse was exposed to ultrasound for 15,30 and $60 \mathrm{~min}$ in alkaline $(0.005 \%$ or $5 \%$ $\mathrm{NaOH}(\mathrm{m} / \mathrm{v}))$ and acid $(0.002 \%$ or $2 \% \mathrm{HCl}(\mathrm{v} / \mathrm{v}))$ medium. The best result was obtained after 30 min of exposure to the alkali, using $5 \% \mathrm{NaOH}$ $(\mathrm{m} / \mathrm{v})$. In this case, the highest amount of \%TRS was obtained. The pretreatments of lignocellulosic materials with $\mathrm{NaOH}$ promoted the swelling of the fibers and increased their hydrophilicity. Thus, the fibers became more susceptible to the hydrolysis reagents, increasing the conversion to TRS. The amount of glucose obtained after the hydrolysis process was determined by HPLC and the findings revealed that alkaline pretreatments favor the production of glucose.

\section{REFERENCES}

1 G. Marrugo, C. F. Valdés and F. Chejne, Energ. 31, 9 (2017), https://doi.org/10.1021/acs.energyfuels.7b00665

2 CONAB, "Acompanhamento da safra brasileira cana-de-açucar" [Follow-up of the Brazilian harvest sugarcane], agro/safras/cana, Brazil, 2019

3 R. S. Ramalho, "O uso de macerado no estudo anatômico de madeiras", UFV, Viçosa, 1987, pp. 4, http://www.scielo.br/scielo.php?script=sci_nlinks\&ref $=000131 \&$ pid $=$ S0100$6762200600020001800017 \& \operatorname{lng}=\mathrm{pt}$

4 J. C. L. Linares, I. Ballesteros, J. Tourán, C. Cara and E. Castro, Bioresour. Technol., 190, 97 (2015), http://dx.doi.org/10.1016/j.biortech.2015.04.066

5 N. Sarkar, S. K. Ghosh, S. Bannerjee and K. Aikat, Renew. Energ., 37, $19 \quad$ (2012), http://dx.doi.org/10.1016/j.renene.2011.06.045 
6 X. Xua, E. Jiang and X. Lan, Bioresour. Technol., 239, 97

(2017), http://dx.doi.org/10.1016/j.biortech.2017.04.083

7 C. Zhang, H. Wen, C. Chen, D. Cai, C. Fu et al., Renew. Energ., 134, $44 \quad$ (2019), https://doi.org/10.1016/j.renene.2018.11.005

${ }^{8}$ G. Ji, W. Xiao, C. Gao, Y. Cao, Y. Zhang et al., Energ. Convers. Manage., 171, 38 (2018), https://doi.org/10.1016/j.enconman.2018.05.087

9 M. J. Taherzadeh and K. Karimi, BioResources, 2, 472 (2007),

https://ojs.cnr.ncsu.edu/index.php/BioRes/article/view/ BioRes_2_4_707_738_Taherzadeh_Karimi_EnzymeB ased_Hydrol_Ethanol_Review

10 S. Gámez, J. J. G. Cabrialesa, J. A. Ramírez, G. Garrote and M. Vázquez, J. Food Eng., 74, 78 (2006), https://doi.org/10.1016/j.jfoodeng.2005.02.005

11 Y. Hu, S. Feng, C. C. Xu and A. Bassi, Fuel, 206, 300 (2017), https://doi.org/10.1016/j.fuel.2017.06.021

12 P. Leite, J. M. Salgado, A. Venâncio, J. M. Domínguez and I. Belo, BioResources, 214, 737 (2016), https://doi.org/10.1016/j.biortech.2016.05.028

13 X. Yua, X. Bao, C. Zhou, L. Zhang, A. E. A.Yagoub et al., Ultrason. Sonochem., 41, 410 (2018), https://doi.org/10.1016/j.ultsonch.2017.09.003

14 A. K. Lee, D. M. Lewis and P. J. Ashman, Biomass

Bioenerg., $\quad 46, \quad 89 \quad$ (2012), https://doi.org/10.1016/j.biombioe.2012.06.034

15 G. L. Miller, Anal. Chem., 31, 426 (1959)

16 L. Segal, J. J. Creely, A. E. Martin and J. C. M. Conrad, Text. Res. J., 29, $786 \quad$ (1959), https://doi.org/10.1177/004051755902901003

17 A. S. Do Amaral, A. A. C. Cunha, O. A. C. Santos and B. M. Lucia, Materia-Rio de Janeiro, 23 (2018), https://doi.org/10.1590/s1517-707620180004.0594

18 A. A. C. Cunha, O. A. C. Santos, B. W. M. Silva, B. M. Lucia et al., Materia-Rio de Janeiro, 22 (2017), http://dx.doi.org/10.1590/s1517-707620170003.0200

19 L. V. A. Gurgel, K. Marabezi, L. A. Ramos and A. A. S. Curvelo, Ind. Crop. Prod., 36, 560 (2012), https://doi.org/10.1016/j.indcrop.2011.11.009

${ }^{20}$ G. Cruz, P. A. Santiago, C. E. M. Braz and P. Seleghim, J. Therm. Anal. Calorim., 132, 2 (2018), https://doi.org/10.1007/s10973-018-7041-1

21 D. M. Carvalho, J. H. Queiroz and J. L Colodettea, Ind. Crop. Prod., 94, $932 \quad$ (2016), https://doi.org/10.1016/j.indcrop.2016.09.069

22 C. Sakdaronnarong and W. Jonglertjunya, Science Asia, $38, \quad 364$ (2012), https://doi.org/10.2306/scienceasia15131874.2012.38.364

${ }^{23}$ P. Alvira, E. Tomás-Pejó, M. Ballesteros and M. J. Negro, BioResources, 101, 4851 (2010), https://doi.org/10.1016/j.biortech.2009.11.093 